\title{
Patient Satisfaction Measurement For In-Hospital Services Delivered By Nurses: Guidelines For Improving Practice In Africa
}

\author{
P. Kokou, University of Johannesburg, South Africa \\ E. Van Tonder, North West University, South Africa \\ M. Roberts-Lombard, University of Johannesburg, South Africa
}

\begin{abstract}
Hospitals in developing countries in Africa cannot focus on improving only the technological and operational side of their service offering in trying to adhere to the stipulations of the World Health Organization. To truly become competitive and remain viable over the long term, hospitals would also need to attend to their services marketing strategies and ensure that the level of patient service offered is of high quality. Consequently, the primary objective of the research reflected in this article was to explore the level of service provided by the nursing staff at the military hospital in Libreville, Gabon, with regard to the variables of reliability, responsiveness, assurance and empathy. The military hospital has been very successful in attracting more patients, and their achievements could provide valuable guidance to other hospitals on the African continent to improve their practices. The population was defined as all existing patients of the military hospital in Gabon. A systematic probability sampling technique was applied and self-administered questionnaires were distributed to the patients once they had signed the released form. The findings revealed that, in respect of the level of service experienced, the nurses were more successful in addressing the empathy and assurance dimensions of service quality than the responsiveness and reliability dimensions. Overall, though, it seems that all the dimensions measured in the study were adequately addressed by the nurses. By incorporating these dimensions into their services marketing strategies, hospitals in Africa could benefit from improved service quality, patient loyalty, market share, and profit.
\end{abstract}

Keywords: Health Care Industry; Services Marketing; Service Dimensions; Patient Satisfaction

\section{INTRODUCTION}

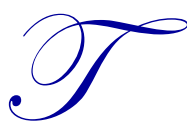

he medical industry on the African continent is at a turning point (The Economist Intelligence Unit, 2012 , p. 2). Adhering to the requirements of the World Health Organization $(2007$, p. 1$)$ that every person has the right to the highest attainable standard of health, numerous health care organisations have been established over the past few decades to improve the living conditions of people in member countries. These include, for example, an organisation to coordinate the fight against endemic diseases in central Africa, namely OCEAC (Organisation de Coordination pour la lutte contre les Endémies en Afrique Centrale), and the Central African Economic and Monetary Community, which aims to support economic growth and cooperation and to improve the living conditions of people in member countries (Organe exécutif de la CEMAC, 2012; Bourgarel, Wauquier \& Gonzalez, 2010). While these organisations do make a valuable contribution in improving the standard of health care in Africa, more work is required to ensure that the health care industry on the African continent will still be viable over the next decade (The Economist Intelligence Unit, 2012, p. 4). Some of the critical interventions necessary include mobile technologies to provide greater access to health care, an improved distribution system for medical supplies, making health insurance coverage available to poor Africans, and ensuring that the health care system is fit for purpose (The Economist Intelligence Unit, 2012, pp. 4, 5, 30). It further seems that hospitals in Africa would also need to focus on services marketing and the provision of quality services to ensure their viability 
over the long term. Naik, Gantasala and Prabhakar (2010, p. 239) maintain that service quality in health care is fundamental for satisfying patients and making them loyal. Other scholars in the field uphold the same view. Various studies have indicated a positive relationship between service quality in hospitals, patient satisfaction and loyalty (Olusoji, 2009, p. 7).

Quality often leads to patient satisfaction. Satisfied patients are more likely to remain faithful, which leads to a positive reputation by word of mouth and an increase in hospital profitability (Desai, 2011, p. 41). The core idea is that for a service organisation to grow, its customers must be satisfied. Happy customers are more likely to return to the organisation and to use its services again. Customers spend their money to acquire services that must satisfy their needs. Such services must have an optimum level of quality and reliability and must be offered to consumers at the right price and be advertised effectively to attract them (Fornell, Rust \& Dekimpe, 2010, p. 29).

In order to understand service quality and satisfaction in health care, it is necessary to investigate various dimensions of service quality considered to influence patient satisfaction (Desai, 2011, p. 40). Kasper, Helsdingen and Gabbott (2006, p. 189) note the five major attributes of service quality as reliability, responsiveness, assurance, empathy and tangibility. To date, however, little research has been conducted - in developing African countries specifically - to measure hospital staff's performance in relation to the service quality dimensions, and to identify problems in connection with poor service delivery. This could be useful in obtaining insight into the dimensions of service quality that have been adequately addressed by an African hospital. Knowledge of the hospital's success stories could provide valuable guidance for other hospitals on the African continent to improve their practices.

Consequently, to assist in addressing the research gap that exists in the African medical environment, this article reports on research undertaken to measure patient satisfaction with hospital services delivered by a military hospital in Gabon. The hospital, located in the main capital of Libreville, has been operating since 2005. The facility has been reputed for attracting many patients in the region (Hôpital d'instructions des armées, 2011). While many staff members play a part in the provision of services at the military hospital, the study focused only on the service provided by the nurses at the hospital. It was argued that the patients who stay over at the hospital have to deal mostly with the services of the nursing staff, who have to take care of their medical as well as emotional needs and nurse them back to health.

\section{RESEARCH PROBLEM}

Patient satisfaction results from quality in health care. Through health services marketing, health care institutions can market their offerings to gain more customers and become more competitive. Studies have indicated that services marketing has a greater effect on patients' behaviour than the costs they have to endure in hospitals. As a result, services marketing can portray a positive image of the hospital, which in turn encourages patients to remain more loyal and refer the facility to others (Dosen, 2009, p. 2007). Services marketing can be approached as a tool for managing, identifying and satisfying customer requirements. It concentrates on the distinctive features of services and how they can be properly managed in order to impact both consumer behaviour and the entire organisation (Lovelock, Wirtz, \& Chew, 2011, p. 45). Understanding consumers' service needs and anticipating their requirements are fundamental aspects of the marketing of services (Zeithaml, Bitner, \& Gremler, 2009, p. 8).

Within this services marketing domain, the quality of services provided often plays a critical role in satisfying patients and making them loyal. It is consequently essential for hospitals on the African continent to focus on the dimensions of service quality and ensure that their service delivery is of a high standard. To date, however, little research has been conducted to provide hospitals on the African continent with more guidance to improve their practices regarding the provision of service quality. Knowledge of the dimensions of service quality that are adequately addressed by the nursing staff at the military hospital in Gabon could assist in addressing the research gap that exists in the medical environment in Africa. The military hospital has been very successful in attracting new patients, and insight into the service quality practices of the hospital could assist other hospitals on the African continent to deliver the highest attainable standard of the health (as required by the World Health Organization) and to become more viable over the next decade. 


\section{THEORETICAL BACKGROUND}

This section is devoted to a literature review to obtain more insight into the context of the study and to assist with the formulation of the research objectives.

\section{Health Development Initiatives in Gabon}

Over the past few decades the number of medical facilities in Gabon has increased from 28 in 1985 to 87 in 2011. In addition, 312 dispensaries and infirmaries were also created. There are 29 medical doctors available for every 100000 individuals. The state in Gabon is perceived as the main supplier of health services in the country. As a result, most of the medical institutions in the country are owned by the state. There are also private institutions that offer medical services to the inhabitants. In Gabon $90 \%$ of the population can access medical services offered by the state; the remaining $10 \%$ of the citizens can access medical services offered by private institutions (Health and safety in Gabon, 2011).

Private clinics and hospitals are accessible in bigger cities, and they offer a broader range of superior health services. However, these facilities are costly to the population, and hospitals generally require immediate cash payment before patients can be treated and/or admitted. People either pay cash for treatment or use a medical cover plan to have access to medical services. Two out of three of the people in Gabon live below the poverty line, and as a result only a few people can actually afford access to private health care services (Cremers, Janssen, Huson, Bikene, Bélard, Gerrets \& Grobusch, 2013, p. 329-330).

Government expenditure on health per capita amounts to $\$ 130$ per person, which represents 4.5 per cent of the national gross domestic product. This ranks the country third after Seychelles (\$382) and Botswana (\$135) per person. Unfortunately, the government's investment has often not been utilised to its full potential. Financial resources have to be properly managed in order to meet the country's health development initiatives. Medical services in the country lack innovation and they can no longer address the needs of the people (Health, 2007, p. 21).

Furthermore, despite the growth in the number of medical facilities, a travel advisory issued by the US Department of State (2010) observed that most of the medical facilities in Gabon still remain limited in terms of proper infrastructure, sanitation, medical practices, qualified medical staff and technology. A transformation in the health care industry is required to achieve the four major target initiatives, such as raising the number of both private and public hospitals so that the entire population can have access to quality care. This includes enhancing the health of mothers, newborns and children, since healthy mothers are more likely to have healthy babies, and healthy children are the future of the country. All people need to be provided with affordable medicines, and universal medical cover based on the European model has to be implemented for the whole Gabonese population. The idea is to increase accessibility to proper medical services for more people (Médécine interne, 2010).

In contrast to the state and private hospitals described above, the military hospital in Gabon appears to be one of the more successful health care institutions and has attracted a large number of patients. The hospital opened its doors in 2007 and offers services to the general public. A number of local and international medical professionals are employed at the hospital, and each department has advanced medical equipment ranging from ultramodern air conditioners, computers, X-ray machines, scanners, and audiometric, echograph, electrocardiograph, radiology, endoscope and echocardiograph machines (Historique, 2010).

The chief medical director, who is also a medical specialist, and the heads of clinical departments serve on the hospital's executive panel. The departments include: internal medicine; emergency; medical analysis; pharmacy; surgery and orthopaedic; ophthalmology; ear nose and throat; and radiology. The research conducted for this article explored only the service delivered by the nurses in the internal medicine department. The internal medicine department includes a team of medical specialists such as dermatologists, cardiologists and nurses (Médécine interne, 2010). 


\section{Services Marketing in Health Care Organisations}

Services marketing in the hospital industry refers to the planning, implementation and control of medical services delivery designed to target patients' needs through the use of an effective, price-conscious, communication and distribution strategy (Dosen, 2009, p. 205). Services marketing has become the focus point of most health care organisations, and hospitals are now willing to invest in services marketing. The underlying reason for this behaviour may be either that there are a growing number of medical institutions in the same region or that resources and customers have become scarce and competition between medical institutions has intensified. Services marketing holds great benefits for health care organisations, because if the patients' expectations are met, the result can be a positive word-of-mouth reputation, patient loyalty, hospital profitability, and patient satisfaction with medical care (Dosen, 2009, p. 206; Olusoji, 2009, p. 7).

\section{Service Quality and Patient Satisfaction}

The provision of quality services is an important aspect within the services marketing domain. Service quality can be defined as the delivery of excellent or superior services relative to customer expectations (Rezaei, Rezaei, Alipour, \& Salehi, 2011, p. 485). Patients, however, value services in health care more for their functional quality than for their technical quality (Yesilada \& Direktor, 2010, p. 963). Technical quality relates to the precision of the medical process that leads to cure, while functional quality refers to the way medical services are administered to patients, such as with care. Patients value the interpersonal relationships with medical staff (Mekoth et al., 2012, p. 17-18).

Services quality is furthermore strongly correlated to patient satisfaction in health care. Superior services often lead to a high degree of patient satisfaction, retention and loyalty (Olusoji, 2009, p. 7). Kim (2008, p. 1156) confirms that the level of services provided in medical care is a predecessor of satisfaction or dissatisfaction.

Satisfaction refers to the consumer's fulfilment response. It is the subjective evaluation that a service offers a pleasurable degree of consumption-related fulfilment (Olusoji, 2009, p. 12). Customer satisfaction has become a major concern and focus in marketing. Research has shown that satisfaction surveys have been widely used in various organisations to evaluate service quality. Customer satisfaction has an effect on the profitability of nearly every organisation. When customers are satisfied with services, they will more likely tell others. However, a lack of customer satisfaction has a negative effect on the bottom line. Customer satisfaction is an asset that should be monitored and managed just like any physical asset (Bodet \& Assolant, 2011, p. 783).

\section{Assessment of Level of Service Provided}

In general there are five major attributes that can be measured to assess the level of service quality provided by medical staff, namely reliability, responsiveness, assurance, empathy and tangibility (Kasper et al., 2006, p. 189). Each of these dimensions is briefly described below:

- Reliability: This refers to the ability to provide the service correctly and dependably, such as keeping appointments consistently, completing duties on time, and keeping promises to patients (Al-Alak \& Alnaser, 2012, p. 157).

- Responsiveness: This refers to the willingness to help customers. Service providers must be willing to respond to individual customer needs and make sure that customers remain involved (Kasper et al., 2006, p. 190).

- Assurance: This encompasses competence, courtesy, credibility and security. The assurance element involves training employees to acquire knowledge of the service delivery process and customer relationship. It is vital to provide excellent services and create the perception that the service provider is competent and not going to harm anyone. This approach can also build trust in the customer's mind (Meng, Summey, Herndon, \& Kwong, 2009, p. 775).

- Empathy: This includes communication, access and understanding. It focuses on the communication between the service provider and the recipient of the service. In hospitals, empathy is reflected in the ability of medical personnel to care for their patients (Al-Alak \& Alnaser, 2012, p. 157). 
- Tangibility: This refers to the tangible aspects of service such as the condition of physical facilities, equipment and the appearance of employees. These elements can have a great impact on perceived service quality. In hospitals, for instance, cleanliness of premises, staff appearance, decor, computers and medical equipment can all have a positive or negative impact on the patient's perceptions of service quality (Kasper et al., 2006, p. 189). For the purpose of this article, tangibility was not assessed since it does not relate to the behaviour of nurses towards their patients. Tangibility is concerned with the physical environment, whereas the study wished to assessed the quality of service patients expected and experienced from nurses at a military hospital in Gabon. Therefore, only four dimensions were used to measure the level of service quality patients received from their nurses, namely reliability, responsiveness, assurance and empathy.

\section{OBJECTIVES}

Emanating from the research problem and the literature review provided, the primary objective of the study conducted for this article was twofold: firstly to assess patients' perception of the level of service provided by their nurses at the military hospital in Gabon; and secondly to provide guidelines for improving practice in Africa.

The following secondary objectives were formulated to assist in addressing the primary research objective:

- $\quad$ To assess the level of service patients expected nurses to deliver at the military hospital in Gabon, with regard to the variables of reliability, responsiveness, assurance and empathy.

- $\quad$ To assess the level of service patients experienced from nurses at the military hospital in Gabon, with regard to the variables of reliability, responsiveness, assurance and empathy.

- $\quad$ To establish whether there is a significant difference between the levels of service patients expected and experienced from nurses at the military hospital in Gabon.

- $\quad$ To establish the dimensions of service quality that were adequately addressed by the nurses at the military hospital in Gabon.

- $\quad$ Considering the experiences of patients with regard to the services delivered by nurses, to identify which of the four service dimensions examined have a significant positive relationship with the dependent variable of general patient satisfaction at the military hospital in Gabon.

- To make recommendations for service improvement at the military hospital in Gabon and the rest of Africa.

\section{HYPOTHESES}

The following hypotheses were tested in order to assist in meeting the research objectives:

$\mathbf{H A}^{1}$ : There is a significant difference between the levels of service patients expected and experienced from nurses at the military hospital in Gabon.

$\mathbf{H A}^{2}$ : Considering the experiences of patients with regard to the services delivered by nurses, the independent variables of reliability, responsiveness, assurance and empathy all have a significant positive relationship with the dependent variable of general patient satisfaction at the military hospital in Gabon.

\section{METHODOLOGY}

The study followed a descriptive survey research design that was quantitative in nature. The population was defined as all patients of the military hospital in Libreville, Gabon, 18 years or older, males and females, who were hospitalised there for at least one night. The population elements were chosen mainly because more than 80 per cent of patients visiting the military hospital had to receive in-hospital medical treatment. In addition, the patients who had to stay over at the hospital had the opportunity to experience the quality of the hospital rooms as well as the treatment received. The sample selected was defined as all patients who received treatment at the military hospital during March 2013 and who matched the sampling frame. The systematic probability sampling technique was used to select the sample. Every second patient who had to stay over at the hospital for at least one night was requested to complete the questionnaire once they had signed the release form. If a patient was not willing to participate in the 
survey, the next patient was selected, and thereafter the next willing patient. The nurse manager of the department of internal medicine of the hospital provided permission to conduct the survey there. The scale items used in the research questionnaire were adapted from the studies previously completed by Doghaither, Abdelrhman, Saeed, and Magzoub (2003) as well as Holder (2008) that specifically tested the service quality statements in the hospital industry. The questionnaire consisted of a series of structured, closed-ended questions that were based on a sevenpoint Likert scale. The wording of some of the statements was slightly modified to ensure that they would collect information regarding the respondents' perceptions of the level of service expected and experienced from nurses at the military hospital. However, the researchers ensured that the current study would still assess the same matters that Doghaither et al. (2003) and Holder (2008) initially explored in their research. The first part of the questionnaire (section A) was concerned with collecting information regarding the socio-demographic profiles of the respondents. The second part of the questionnaire (section B) focused on the dimensions of service quality, namely reliability, responsiveness, assurance and empathy. The respondents were requested to use the scale provided and assess the level of service they expected as well as experienced from the nurses at the hospital. The third part of the questionnaire (section C) evaluated the respondents' overall perceptions of the services received from the hospital.

A pilot study was conducted first to correct any errors in the design of the questionnaire. Five patients who had to stay over at the military hospital for at least one night were requested to complete the questionnaire. The pretesting phase revealed that some of the respondents were not fluent in English and experienced difficulty in understanding the questions. Consequently, using a forward and backward translation technique, the measuring instrument was translated into French (the main language spoken in the study location). A total of 200 completed questionnaires were received. After the data was coded, captured and edited, SPSS version 18 was used to analyse the data. Cronbach's alpha was used to assess the reliability of the scales in sections B and C of the questionnaire. The content of the questionnaire was further aligned with the research objectives formulated, to assist in ensuring that the study would measure what it was intended to measure. Descriptive statistics, paired sample t-tests, as well as Spearman's rank order correlation coefficients were utilised to analyse the data and to test the study's hypotheses.

\section{RESULTS}

\section{Demographic Profile of Respondents}

The demographic characteristics of the respondents are shown in Table 1. 
Table 1. Demographic Characteristics of the Respondents

\begin{tabular}{|c|c|c|}
\hline \multicolumn{2}{|c|}{ Demographic Variable } & \multirow{2}{*}{$\begin{array}{c}\text { Percentage } \\
73.5 \%\end{array}$} \\
\hline & 1) Male & \\
\hline Gender & 2) Female & $26.5 \%$ \\
\hline \multirow{5}{*}{ Age } & 1) $18-28$ & $17.0 \%$ \\
\hline & 2) $29-38$ & $13.0 \%$ \\
\hline & 3) $39-49$ & $38.0 \%$ \\
\hline & 4) $50-60$ & $20.0 \%$ \\
\hline & 5) 61 and above & $12.0 \%$ \\
\hline \multirow{4}{*}{ Highest educational level } & 1) No formal education & $12.1 \%$ \\
\hline & 2) Primary education & $3.0 \%$ \\
\hline & 3) Secondary education & $29.8 \%$ \\
\hline & 4) Tertiary education & $55.1 \%$ \\
\hline \multirow{5}{*}{ Marital status } & 1) Single & $15.2 \%$ \\
\hline & 2) Married & $64.5 \%$ \\
\hline & 3) Divorced & $9.6 \%$ \\
\hline & 4) Widowed & $10.2 \%$ \\
\hline & 5) Cohabitant & $0.5 \%$ \\
\hline \multirow{7}{*}{ Employment level } & 1) Employed full-time & $62.5 \%$ \\
\hline & 2) Employed part-time & $7.0 \%$ \\
\hline & 3) Self-employed in formal sector & $10.5 \%$ \\
\hline & 4) Self-employed in informal sector & $7.0 \%$ \\
\hline & 5) Unemployed & $1.0 \%$ \\
\hline & 6) Student & $2.5 \%$ \\
\hline & 7) Pensioner (older age) & $9.5 \%$ \\
\hline \multirow{2}{*}{ Residential area } & 1) In Libreville & $64.5 \%$ \\
\hline & 2) Outside of Libreville & $35.5 \%$ \\
\hline \multirow{2}{*}{$\begin{array}{l}\text { First visit to hospital as a } \\
\text { patient? }\end{array}$} & 1) Yes & $81.4 \%$ \\
\hline & 2) No & $18.6 \%$ \\
\hline \multirow{2}{*}{$\begin{array}{l}\text { Required to stay over for at } \\
\text { least one night? }\end{array}$} & 1) Yes & $100 . \%$ \\
\hline & 2) $\mathrm{No}$ & $0 \%$ \\
\hline
\end{tabular}

Of the 200 patients who completed the survey, almost three-quarters $(73.5 \%)$ were males and the rest (26.5\%) were females. It further seems that almost two-thirds of the patients were married (64.5\%), followed by the single group (15.2\%), the widowed group (10.2\%), the divorced group (9.6\%) and the cohabitant group (0.5\%).

It can further be deduced from Table 1 that the age groups 39-49 years (38.0\%) and 50-60 years (20.0\%) were selected most, and, together with the age group 18-28 years (17.0\%), represent the majority of the patients who completed the survey. Finally, it seems that most of the patients had progressed to either a secondary educational level $(29.8 \%)$ or a tertiary educational level $(55.1 \%)$, were located in Libreville (64.5\%), had full-time employment $(62.5 \%)$, and had been receiving treatment at the military hospital for the first time (81.4\%). All the respondents who participated in the study (100\%) were also required to sleep over at the hospital for at least one night.

\section{Reliability}

The reliability statistics calculated for the study are displayed in Table 2. 
Table 2. Reliability Statistics

\begin{tabular}{lcc}
\hline \multicolumn{1}{c}{ Dimensions of SERVQUAL } & Number Of Items & Cronbach's Alpha Value \\
\hline Expectation & & 0.831 \\
\hline Reliability & 4 & 0.734 \\
Responsiveness & 4 & 0.612 \\
Assurance & 4 & 0.628 \\
Empathy & 4 & \\
\hline Experience & & 0.767 \\
\hline Reliability & 4 & 0.717 \\
Responsiveness & 4 & 0.816 \\
Assurance & 4 & 0.666 \\
Empathy & 4 & 0.796 \\
General patient satisfaction & 5 & \\
\hline
\end{tabular}

Table 2 indicates that all the Cronbach's alpha values for the measurement sets used in the study are above 0.6, the minimum value acceptable for research (Malhotra, 2010, p. 319). The Cronbach's alpha coefficients for the assurance and empathy constructs were initially less than 0.6. The values increased, however, after the statements "showing respect and dignity towards patients" and "providing patients with individual attention" were disregarded for further analysis. It can consequently be concluded that all the scales used in the measurement instrument were in fact reliable.

\section{Significant Differences between Levels of Service Expected and Experienced}

The first three secondary objectives formulated for the study aimed at establishing the levels of service patients expected and experienced from their nurses at the military hospital in Gabon and whether there was a significant difference between their expectations and the actual service delivered. The statistical results are displayed in Table 3.

Table 3. Comparison of Services Expected and Experienced from Nurses

\begin{tabular}{llcccccc}
\hline \multirow{2}{*}{$\begin{array}{c}\text { Factor } \\
\text { Number }\end{array}$} & $\begin{array}{c}\text { Service Quality } \\
\text { Dimension }\end{array}$ & \multicolumn{2}{c}{ Mean Score } & & & Service Quality & $\begin{array}{c}\text { Ranking (Based on } \\
\text { Least Service Quality } \\
\text { Gap) }\end{array}$ \\
\cline { 3 - 4 } 1 & Reliability & 6.5 & 6.0 & -12.403 & 0.00 & -0.5 & 3 \\
2 & Responsiveness & 6.4 & 6.2 & -8.895 & 0.00 & -0.2 & 1 \\
3 & Assurance & 6.7 & 6.4 & -6.563 & 0.00 & -0.3 & 2 \\
4 & Empathy & 6.9 & 6.7 & -4.970 & 0.00 & -0.2 & 1 \\
\hline
\end{tabular}

Table 3 reflects the mean scores that were obtained with regard to the four service quality dimensions of reliability, responsiveness, assurance and empathy. The paired sample t-test was used to determine if there is a significant difference between the perceptions of the respondents regarding the levels of service expected and experienced from the nurses at the military hospital in Gabon.

The data set complied with all the underlying assumptions required to perform the paired sample t-test evaluation. The respondents were randomly selected; observations obtained for the study are not related to each other; the data set has a normal distribution; and more than 30 respondents were interviewed. Table 3 shows that there are statistically significant differences between the perceptions of services expected and experienced from nurses, with regard to all the variables investigated. More particularly, there was a statistically significant decrease in the score of the reliability construct from expectation $(M=6.5, S D=0.4)$ to experience $(M=6.0, S D=0.4), t$ $(199)=-12.403, \mathrm{p}<0.0005$ (two-tailed). Secondly there was also a statistically significant decrease in the responsiveness scores from expectation $(M=6.4, S D=0.4)$ to experience $(M=6.2, \mathrm{SD}=0.5), \mathrm{t}(199)=-8.895, \mathrm{p}<$ 0.0005 (two-tailed). Thirdly, there was a statistically significant decrease in the assurance scores from expectation $(M=6.7, S D=0.4)$ to experience $(M=6.4, S D=0.6), \mathrm{t}(195)=-6.563, \mathrm{p}<0.0005$ (two-tailed). Lastly, there was also a statistically significant decrease in the empathy scores from expectation $(M=6.9, S D=0.3)$ to experience $(M$ $=6.7, S D=0.4), \mathrm{t}(199)=-4.970, \mathrm{p}<0.0005$ (two-tailed). The mean decrease in scores is also portrayed in Table 3 . It seems that the gap with regard to service expected and experienced is the smallest concerning the empathy and responsiveness constructs and the largest concerning the reliability construct. The effect sizes calculated, using eta 
squared, for each of the variables were respectively 0.436 (reliability), 0.283 (responsiveness), 0.181 (assurance) and 0.110 (empathy). Considering these results and the guidelines provided by Pallant (2010, p. 247), the actual difference in mean scores between the groups (with regard to all the constructs measured) can be regarded as relatively small.

Consequently, following the above discussion, the first research hypothesis that was formulated for the study, namely that there is a significant difference between the levels of service patients expected and experienced from nurses at the military hospital in Gabon, can be accepted. Statistically significant differences were found between the perceptions of all the groups investigated. However, the difference between the levels of service expected and experienced from the nurses at the military hospital is relatively small. Finally, it also appears that concerning the fourth secondary objective formulated for the study, the nurses at the military hospital in Gabon were more successful in addressing the empathy and assurance dimensions of service quality than the responsiveness and reliability dimensions, when considering the respondents' rating of level of service experienced. The mean result of 6.7 obtained for the empathy dimension and the mean result of 6.4 obtained for the assurance dimension were higher than the mean results obtained for the responsiveness (6.2) and reliability (6.0) dimensions (with regard to services experienced). However, if the researchers bear in mind the level of service which the respondents expected, it can be argued that the nurses were more effective in addressing the responsiveness and empathy dimensions, since the service gap between these two dimensions and general patient satisfaction was the smallest. From a holistic perspective, it can then further be noted that according to the Likert scale provided, a mean result of 6.0 reflects that the respondents mostly agreed with all the statements listed in the scale. The mean scores displayed in Table 3 with regard to service experienced were all above 6.0, thereby indicating that the respondents were satisfied overall with the level of service experienced from the nurses. Furthermore, since the difference between the levels of service expected and experienced is also relatively small, it can be concluded that all the dimensions measured in the study were adequately addressed by the nurses.

\section{The Relationship between the Independent Variables and General Patient Satisfaction at the Military Hospital in Gabon}

The fifth secondary objective formulated for the study aimed at determining which of the four service dimensions that measured service experience have a significant positive relationship with the dependent variable of general patient satisfaction at the military hospital in Gabon. The preliminary analyses revealed that not all the variables investigated were related in a linear fashion. Consequently, Spearman's rank order correlation technique was applied to determine the relationship between the independent variables and the dependent variable. The results are displayed in Table 4.

Table 4. Correlations between Independent Variables and General Patient Satisfaction

\begin{tabular}{lccc}
\hline Factors & Correlation Coefficient & Sig. (Two-Tailed) & Coefficient of Determination \\
\hline Reliability & -0.175 & 0.013 & $3.1 \%$ \\
Responsiveness & -0.133 & 0.061 & $1.8 \%$ \\
Assurance & 0.191 & 0.007 & $3.6 \%$ \\
Empathy & 0.377 & 0.000 & $14.2 \%$ \\
\hline
\end{tabular}

Table 4 shows that the variables assurance and empathy are significantly positively correlated with the dependent variable general patient satisfaction, at the $\mathrm{p}<0.025$ level (two-tailed). Considering the guidelines provided by Pallant (2010, p. 134), the strength of the relationship between assurance and general patient satisfaction can be regarded as small, and the strength of the relationship between empathy and general patient satisfaction can be regarded as medium. Table 4 further indicates that there is no significant relationship between the variable responsiveness and general patient satisfaction $(\mathrm{p}>0.025)$. The inverse relationship between the two variables could subsequently have occurred due to chance. Table 4 also indicates that there is a significant inverse relationship between the variable reliability and general patient satisfaction $(p<0.025$, two-tailed). These findings point to the fact that reliability decreases as general patient satisfaction still increases. Consequently, the model predicts the probability that based on the current level of reliability, patients will still be generally satisfied with the service received from the hospital. It is therefore implied that among the patients at the military hospital in Gabon, the reliability of the nurses' service is not a basis for general patient satisfaction at the hospital. A possible reason for 
the scenario could be that because most of the patients were visiting the hospital for the first time, they were not really in a position to form an opinion about the consistency of the nurses' level of service provided and how it would impact on their overall level of customer satisfaction. Furthermore, the inverse relationship between reliability and general patient satisfaction is weak (less than 0.3) and it seems that the hospital management should not be greatly concerned about reliability in their endeavours to improve the level of general satisfaction of patients.

Lastly, the coefficient of determination results displayed in the last column of Table 4 additionally show that the variance shared between the independent variables and the dependent variable is less than $15 \%$, thereby indicating that there are also other variables that could have an impact on the level of satisfaction of patients at the hospital. Consequently, given the above findings, it can be concluded that the second hypothesis, stating that the independent variables all have a significant positive relationship with the dependent variable of general patient satisfaction at the military hospital in Gabon, can only be partially accepted. Only the variables assurance and empathy have a significant positive relationship with general patient satisfaction, but the relationship is not very strong.

\section{DISCUSSION}

Following the findings of the study, a number of observations can be made:

Firstly, the literature review established that the military hospital in Libreville, Gabon, in contrast to other hospitals on the African continent, has managed to attract patients and provide them with good service quality. The empirical results confirmed that the military hospital is performing well. The mean scores indicated that the respondents rated the service experienced from the nurses as high with regard to the variables reliability, responsiveness, assurance and empathy. The significant difference between the levels of service expected and received from the nurses was also very small. The nurses were more successful in addressing the empathy and assurance dimensions of service quality than the responsiveness and reliability dimensions, when considering the level of service experienced. If the researchers consider the level of service expected, it seems that the respondents were most effective in addressing the responsiveness and empathy dimensions. However, overall it seems that all the dimensions measured in the study were adequately addressed by the nurses.

Consequently, following these findings, it seems that nurses at the military hospital are successful in providing a reliable service, responding to the needs of their patients, providing assurance and showing empathy towards their patients. In this regard, nurses at the military hospital in Gabon could set a good example to other hospitals on the African continent. Nursing staff at other hospitals could pay particular attention to the skills displayed by nurses at the military hospital in respect of providing assurance, showing empathy towards patients, and being responsive to the needs of their patients. This is justified by the fact that the service gaps between the responsiveness and empathy dimensions and general patient satisfaction were the smallest, and that the assurance and empathy dimensions on average received the highest service experience ratings.

The management team at the hospital, however, would not be able to focus mainly on the abovementioned initiatives to improve the general satisfaction level of patients at the hospital. The relationship between the variables assurance and empathy and the dependent variable general patient satisfaction was not very strong, and each variable contributed less than $15 \%$ of the variance in general patient satisfaction. Also, the variables reliability and responsiveness of the nursing staff cannot be incorporated into the hospital's strategy to improve the general satisfaction of patients. Consequently, it appears that the service dimensions investigated in this study can primarily be considered to improve the level of service quality provided by nurses at a hospital. Service providers in the health care industry wishing to improve the general level of satisfaction of patients at a hospital would need to further identify and investigate other dimensions that might have a greater association with general patient satisfaction at the hospital.

\section{MANAGERIAL IMPLICATIONS}

The findings of the current study has illustrated that patients were satisfied over all the different SERVQUAL dimensions relating to the service delivery of nurses. This finding is consistent with the findings of 
Chunlaka (2010), who found high levels of satisfaction in all five dimensions of the SERVQUAL model. The results of the investigation hold important implications for future planning and development in the African health care industry. Hospital management should take note of the most important service quality issues identified in this investigation relating to the service offering of nurses. Below are recommendations for nurses in guiding their service delivery strategy towards patients at hospitals in Africa.

Nurses should keep in mind that their patients often rely more on the attitudes of the service provider, such as 'care', as an indicator of service quality, rather than the 'curing performance' in health care. Nurses should therefore not only focus on the physical needs of their patients but should also be responsive to the emotional needs of their patients. Patients have a right to individual attention and to be communicated with. As a result, nurses must communicate with patients about their state of health if a doctor is not available at the hospital to do so. Such information can be obtained from the individual patient record at the hospital. It is therefore important for nurses to demonstrate patience and understanding towards the needs of hospital patients. When required to do so, nurses must be knowledgeable and be able to inform patients about their medical treatment or medicine for treatment in a manner that they can understand and feel comfortable with. Therefore, service level standards must be stipulated and the service strategy must be designed from the perspective of the patient and not that of the nurse.

It is furthermore important for nurses to illustrate to patients that they have empathy and understanding for their individual circumstances. Nurses must therefore have a caring attitude towards the individual needs of their patients, ensuring that they are understood in a unique and special manner. This can be achieved through an individualised approach towards understanding the circumstances and condition of the patient. Patients must feel that they are unique and special, are understood, and are important to the nurse who takes care of them. This implies that nurses must have both empathy for, and understanding of, the right of the patient to confidentiality (nurses should not reveal confidential communications or information without the consent of the patient, unless approved by the doctor or provided for by law or by the need to protect the welfare of the individual or the public interest). In addition, nurses should respond to the needs of patients with integrity, and have a desire to help them and provide them with information that they want or need in a manner that they can understand. Furthermore, nurses should maintain trust with patients by never discriminating against them, and should remain honest and act with integrity.

Nurses should also be active listeners towards their patients. They should focus on what the patient is communicating verbally and nonverbally by considering both facts and emotions. Such communication could then be forwarded to the doctor, should this be necessary. Hospital management can also send nurses on educational programmes about interactive communication skills and how to understand and analyse patient behaviour more successfully. Nurses must understand that empathy entails responding to patients' emotional states, helping them deal with their emotional responses, and demonstrating a true sense of caring. Therefore, it is imperative for nurses to always treat their patients with the respect and dignity that they require. Short course training can be provided for nurses on aspects such as emotional empowerment, trauma and death counselling, people behaviour, and how to show empathy. Through such training, nurses can better their skills in building a relationship of trust with their patients.

Nurses must therefore take cognisance of their attitude (feelings and concerns) towards patients and should actively pay attention to both their verbal and nonverbal language. It is not only what nurses communicate to their patients that is important, but also how they communicate their message. Patients must feel that nurses have their personal interests at heart and that they duly care for them. Considering this, it is important that nurses keep patients informed of exactly what the doctor is planning for them and why. Patients need to know what they can expect and how long it will take. If the care of the patient is transferred to another doctor, nurses should inform the patient of the reason for the decision. This will help ease their anxiety. Nurses must keep in mind that ending a patient encounter on a positive note leaves a lasting impression on patients. The more comfortable nurses make their patients feel, the more patients will trust them and follow through with the instructions provided, and the more satisfied they will be.

In conclusion, nurses should be continuously trained through educational programmes to raise their awareness of the importance of patient satisfaction and how to improve the overall quality of their service delivery 
to patients. Such training should enhance the ability of nurses to build rapport with their patients, increase their trustworthiness, and show greater empathy for the personal needs and circumstances of their patients.

\section{LIMITATIONS AND IMPLICATIONS FOR FUTURE RESEARCH}

The current study has provided valuable insight into the factors that hospitals on the African continent could consider to improve the level of service to patients. The empirical findings, however, should be viewed within the framework of certain limitations to the study.

Firstly, only patients in one of the divisions at the military hospital were requested to participate in the survey. The findings therefore do not represent the opinion of all the patients who visited the hospital and can also not be generalised to patients at other hospitals on the African continent. Another research study in future could investigate the same variables on a broader scale to provide more insight into the factors that have an impact on the service quality provided by nurses at a hospital. A more advanced statistical tool, such as structural equation modelling, could also be applied, or the same study could be conducted over different time periods, to investigate the relationship between the independent variables and general patient satisfaction over a greater period of time.

\section{CONCLUSIONS}

Hospitals in developing countries in Africa cannot focus only on improving the technological and operational side of their services offering. To truly become competitive and remain viable over the long term, the hospitals would also need to pay attention to their services marketing strategies. More particularly, the management team would need to focus on ensuring that their nursing staff are able to show empathy towards their patients, provide assurance, be reliable, and be responsive to their needs. The current study, which investigated the practices of nursing staff at the successful military hospital in Libreville, Gabon, discovered that the nurses were more successful in addressing the empathy and assurance dimensions of service quality than the responsiveness and reliability dimensions, when considering the level of service experienced. If the researchers consider the level of service expected, it seems that the nurses were most effective in addressing the responsiveness and empathy dimensions. Overall, though, it seems that all the dimensions measured in the study were adequately addressed by the nurses.

The four service dimensions investigated for the purpose of this article, however, do not seem to have a strong relationship with the level of general patient satisfaction at the hospital. The service dimensions explored can therefore primarily be considered to improve the level of service quality provided by nurses at a hospital. Further research is required to identify the factors that would influence the level of general patient satisfaction at a hospital.

Ultimately, the contribution of this article is in providing some guidance towards improving practices with regard to the quality of service provided by nursing staff at hospitals in Africa. A future research study would need to explore the findings on a broader scale before the results can truly be generalised to patients at other hospitals on the African continent.

\section{AUTHOR INFORMATION}

Ponce Kokou is a Master's degree graduate from the Department of Marketing Management at the University of Johannesburg in South Africa. His research interest is in the domain of Services Marketing.

Mornay Roberts-Lombard is Professor of Marketing at the University of Johannesburg in South Africa. He is a committed member of the local and international research community as journal and book editor, serves on numerous editorial boards and associations. E-mail: mornayrl@uj.ac.za (Corresponding author)

Estelle van Tonder is an Associate Professor of Marketing at the North-West University in South Africa. Her research areas of interest includes Services marketing, Relationship Marketing and Customer Engagement. 


\section{REFERENCES}

Al-Alak, B. A., \& Alnaser, A. S. M. (2012). Assessing the relationship between higher education service quality dimensions and student satisfaction. Australian Journal of Basic and Applied Sciences, 6, 156-164.

Bodet, G., \& Assolant, L. B. (2011). Consumer loyalty in sport spectatorship services: The relationships with consumer satisfaction and team identification. Psychology and Marketing, 28(8), 781-802.

Bourgarel, M., Wauquier, N., \& Gonzalez, J. P. (2010). Emerging viral threats in Gabon: Health capacities and response to the risk of emerging zoonotic diseases in Central Africa. Emerging Health Threats Journal, 3, $1-112$.

Chunlaka, P. (2010). International patients' satisfaction towards nurses service quality at Samitivej Srinakarin Hospital. (Master's degree; unpublished thesis). Srinakharinwirot University, Bangkok.

Desai, V. V. (2011). Case study: Patient satisfaction and service quality dimensions. Journal of Advances Management, 4(5), 40-45.

Doghaither, H. A. I., Abdelrhman, B. M., Saeed, A. A., \& Magzoub, M. E. M. A. (2003). Factors influencing patient choice of hospitals in Riyadh, Saudi Arabia. The Journal of the Royal Society for the Promotion of Health, 123(2), 105-109.

Dosen, D. O. (2009). Perceptions among Croatian surgeons of services marketing application to healthcare organisations. Journal of Health Services Marketing, 21, 203-218.

Fornell, C., Rust, R. T., \& Dekimpe, M. G. (2010). The effect of customer satisfaction on consumer spending growth. Journal of Marketing Research, XL(VII), 28-35.

Forrest, V., Morgeson, L., Mithas, S., Timothy, L., Keiningham, A., \& Aksoy, L. (2011). An investigation of the cross-national determinants of customer satisfaction. Journal of Marketing Sciences, 39, 198-215.

Cremers, A. L.; Janssen, S.; Huson, M. A. M.; Bikene, G.; Bélard, S.; Gerrets, R. P. M.; Grobusch, M. P. (2013). Perceptions, health care seeking behaviour and implementation of a tuberculosis control programme in Lambaréné, Gabon. Public Health Action, 3(4,21), 328-332.

Health. 2007. A healthy future. Gabon Spring Review, 2, 1-88.

Health and safety in Gabon. (2011). Retrieved 26 July 2011 from http://www.spainexchange.com/guide/GAhealth.htmd

Historique. (2010). Hôpital d'instructions des armées. Retrieved 2012 from http://hia-obo.org/fr/historique.php

Holder, S. M. (2008). Changes in physical evidence and the perception of service quality of patients in a hospital facility. (Master's degree. Unpublished Thesis). University of Johannesburg, Johannesburg.

Hôpital d'instructions des armées. (2011). Présentation. Retrieved 25 July 2011 from http://hiaobo.org/Pr\%C3\%A9sentation-42.html

Kasper, H., Helsdingen, P. V., \& Gabbott, M. (2006). Services marketing management: A strategic perspective. $2^{\text {nd }}$ ed. Chichester: John Wiley.

Kim, Y. K. (2008). A study on medical services quality and its influence upon value of care and patient satisfaction: A focus upon outpatients in a large-sized hospital. Total Quality Management, 19, 1155-1171.

Lovelock, C., Wirtz, J., \& Chew, P. (2009). Essentials of services marketing. New York: Prentice Hall.

Malhotra, N. K. (2010). Marketing research: An applied orientation. (6 ${ }^{\text {th }}$ ed.). Upper Saddle River, NJ: Pearson Education.

Médécine interne. 2010. Hôpital d'instructions des armées. Retrieved 2012 from http://hiaobo.org/fr/medecineinterne.php

Mekoth, N., George, P.B., Dalvi, V., Rajanala, N. \& Nizomadinov, K. (2012). Service Quality in the Public Sector Hospitals: A Study in India, Hospital Topics, Vol.90, pp.16-22.

Meng, J. G., Summey, J. H., Herndon, N. C., \& Kwong, K. K. (2009). Some retail service quality expectations of Chinese shoppers. International Journal of Market Research, 51, 773-796.

Naik, K. C. N., Gantasala, S. B., \& Prabhakar, G. V. (2010). Service quality (Servqual) and its effect on customer satisfaction in retailing. European Journal of Social Sciences, 16(2), 231-243.

Olusoji, D. (2009). Perception and patient satisfaction: A case study of Olabisi Onabanjo University Teaching Hospital Sagamu, Nigeria. (MBA degree; unpublished thesis). Blekinge Institute of Technology, Sweden.

Organe exécutif de la CEMAC. (2012). OCEAC. Retrieved 21 July 2012 from http://www.oceac.org/details.php?ref=main\&rubrq=23\&id=40

Pallant, J. (2010). SPSS survival manual: A step by step guide to data analysis using SPSS. (4 ${ }^{\text {th }}$ ed.). Maidenhead, Berkshire: McGraw-Hill Education. 
Rezaei, M. D., Rezaei, H. K., Alipour, H., \& Salehi, S. K. (2011). Service quality, client satisfaction and client personality in the public companies.Australian Journal of Basic and Applied Sciences, 5, 483-491.

Sayed, H. Y., Mohamed, H. A., \& Mohamed, E. E. (2013). Patients' perceptions as indicators of quality of nursing service provided at Al Noor Specialist Hospital at Makkah Al Moukarramah, KSA. Journal of American Science, 9(5), 71-78.

The Economist Intelligence Unit. (2012). The future of healthcare in Africa. Retrieved 2014 from http://www.economistinsights.com/sites/default/files/downloads/EIUJanssen_HealthcareAfrica_Report_Web.pdf

US Department of State. (2010).Travel advisory for Gabon. Retrieved 25 July 2011 from http://travel.state.gov/travel/cis_pa_tw/cis/cis_1120.html

World Health Organization. (2007). The right to health. Retrieved 2014 from http://www.who.int/mediacentre/factsheets/fs323/en/

Yesilada, F., \& Direktor, E. (2010). Health care service quality: A comparison of public and private hospitals. African Journal of Business Management, 4(6), 962-971.

Zeithaml, V. A., Bitner, M. J., \& Gremler, D. D. (2006). Services marketing: Integrating customer focus across the firm. Singapore: McGraw-Hill. 